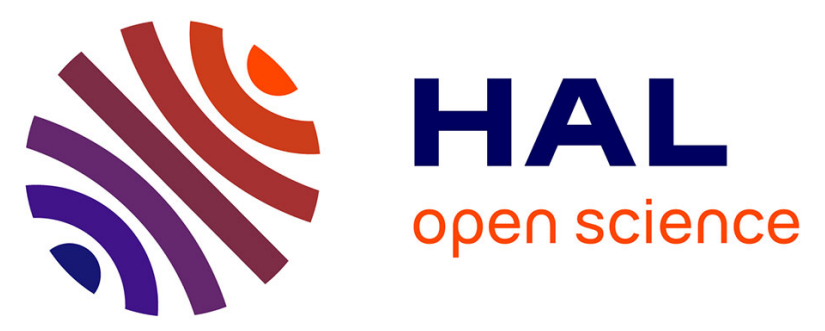

\title{
On the Influence of Yttrium and Sulphur on the High Temperature Oxidation Behaviour of Alumina-Forming High Purity FeCrAl Alloys
}

A. Glazkov, M. Göbel, J. Jedlinski, J. Schimmelpfennig, G. Borchardt, Sébastien J. Weber, S. Scherrer, J. Le Coze

\section{To cite this version:}

A. Glazkov, M. Göbel, J. Jedlinski, J. Schimmelpfennig, G. Borchardt, et al.. On the Influence of Yttrium and Sulphur on the High Temperature Oxidation Behaviour of Alumina-Forming High Purity FeCrAl Alloys. Journal de Physique IV Proceedings, 1995, 05 (C7), pp.C7-381-C7-385. 10.1051/.jp4:1995746 . jpa-00254041

\section{HAL Id: jpa-00254041 https://hal.science/jpa-00254041}

Submitted on 1 Jan 1995

HAL is a multi-disciplinary open access archive for the deposit and dissemination of scientific research documents, whether they are published or not. The documents may come from teaching and research institutions in France or abroad, or from public or private research centers.
L'archive ouverte pluridisciplinaire HAL, est destinée au dépôt et à la diffusion de documents scientifiques de niveau recherche, publiés ou non, émanant des établissements d'enseignement et de recherche français ou étrangers, des laboratoires publics ou privés. 


\title{
On the Influence of Yttrium and Sulphur on the High Temperature Oxidation Behaviour of Alumina-Forming High Purity FeCrAl Alloys
}

\author{
A. Glazkov*,(1), M. Göbel*, J. Jedlinski*,(2), J. Schimmelpfennig, G. Borchardt, S. Weber**, \\ S. Scherrer** and J. Le Coze*** \\ * Technische Universität Clausthal, Metallurgisches Zentrum, SFB 180, Robert-Koch-Str. 42, \\ 38678 Clausthal-Zellerfeld \\ ** Ecole des Mines de Nancy, Laboratoire de Métallurgie Physique et Science des Matériaux, Parc de \\ Saurupt, 54042 Nancy cedex, France \\ *** Ecole des Mines, 42023 Saint-Etienne cedex 2, France
}

\begin{abstract}
Many hypotheses have been published in the literature to explain the beneficial effect of reactive elem ents on the oxidation behaviour of alloys. Although this effect has been known for more than 50 years, the mechanisms involved are not yet very well understood. In order to minimize the influence of impurities in the alloys, in our approach pure metals are used to produce alloys which guarantee well defined starting conditions for two-stage-oxidation experiments. SNMS was chosen to investigate transport phenomena and the growth mechanisms of oxide scale. Sulphur and yttrum yield significant differences in oxide scale composition and microstructure during oxidation at $1200^{\circ} \mathrm{C}$.
\end{abstract}

\section{INTRODUCTION}

The temperatures at which metals are required to operate within oxidizing environments have increased and with these higher temperatures has come a change from the use of chromia-forming alloys to those which form an alumina scale. The great advantage of alumina as a 'barrier' between alloy and oxidizing atmosphere is its low defect concentration and therefore its slow growth rate. Depending on the substrate, alumina tends to spall on cooling and oxide adherence can be very poor. Low level constituents such as sulphur and yttrium influence this behaviour very strongly.

Corrosion studies on $\mathrm{Fe} 20 \mathrm{Cr} 5 \mathrm{Al}$ alloys (used e.g. for furnace resistors) have already been carried out by many authors, e.g. [1-5]. This sort of alloy develops a protective scale of $\mathrm{Al}_{2} \mathrm{O}_{3}$ during oxidation and consequently should have good oxidation resistance at high temperatures.

In studying oxidation mechanisms, oxygen tracer isotopes are commonly used by means of two-stageoxidation experiments, where oxidation in ${ }^{16} \mathrm{O}_{2}$ is followed by oxidation in ${ }^{18} \mathrm{O}_{2}$. SNMS (Secondary Neutral Mass Spectrometry) is used to examine the depth distribution of the two oxygen isotopes and the other constituent elements in the oxide scale.

\section{EXPERIMENTAL}

Four alloys produced by high purity melting were investigated. The preparation of these alloys was made in two steps. At first the metals were purified by chemical and electrochemical processes. Nevertheless for each pure metal, a great number of elements of the periodic table were found :

- Fe : $\Sigma$ impurities $<50$ ppm, 76 elements analyzed

- Cr : $\Sigma$ impurities $<30$ ppm, 73 elements analyzed

- Al : 99,998\%.

\footnotetext{
(i) on leave from RIAM, Moscow.

${ }^{(2)}$ on leave from $\mathrm{AGH}, \mathrm{Cracow}$.
} 
The second step was melting and alloying. Care was taken in the preparation of alloys and subsequent samples in order to (i) obtain good homogeneity of composition, especially when impurities were added and (ii) prevent pollution during heat treatment, forming and machining : the introduction of sulphur and yttrium involved the drilling of a hole in the base ingot, closure of this hole with a pure metal plug and meling of the ingot by induction in a silver cold crucible ${ }^{1}$.

With this procedure four alloys with the following low level constituents were prepared :

Material A : no additions

Material B : sulphur

Material C : yttrium

Material D : sulphur + yttrium.

Table 1 shows details.

\begin{tabular}{||c|c|c|c|c|c|c||}
\hline Material & $\mathrm{Fe}$ & $\mathrm{Cr}$ & $\mathrm{Al}$ & $\mathrm{C}$ & $\mathrm{Y}$ & $\mathrm{S}$ \\
\hline $\mathrm{A}$ & bal & 20.2 & 5.0 & $<10 \#$ &.-- & $<5 \#$ \\
\hline $\mathrm{B}$ & bal & 19.9 & 4.98 & $<10 \#$ & --- & $45 \#$ \\
\hline C & bal & 19.7 & 5.0 & $<10 \#$ & 0.093 & $<5 \#$ \\
\hline D & bal & 20.0 & 4.85 & $<10 \#$ & 0.080 & $15 \#$ \\
\hline
\end{tabular}

values in wt.\%, \#=ppm

Tab. 1 : Chemical composition of the four alloys under investigation

In order to investigate the development of protective alumina scales and matter transport in the growing oxide layers, two-stage oxidation experiments were performed under different conditions (see Table 2).

Before the oxidation experiments were started, all samples were ground, polished and cleaned in a vapour degreasing colum $n^{2}$. After this pretreatment the samples were put into a high vacuum apparatus $\left(\mathrm{p}<2^{*} 10^{-6}\right.$ mbar) and then transferred under vacuum into the hot furnace. After one minute, thermal equilibrium was reached and dried laboratory air could be let in. After the first oxidation step, the system was evacuated quickly (after $20 \mathrm{~s}$ of pumping : $\mathrm{p}<1 * 10^{3}$ mbar, after 1 min of pumping : $\mathrm{p}<5^{*} 10^{5} \mathrm{mbar}$ ) and ${ }^{18} \mathrm{O}_{2}$ was let in. After the second oxidation stage, the gas was pumped back into the storage bottle and simultaneously the specimens were moved out of the furnace, so that the cooling took place under vacuum conditions. The times used for each step of the two-stage-oxidation experiments are listed below (Table 2).

\begin{tabular}{||l|l|l||}
\hline \hline total time & first oxidation step & second oxidation step \\
\hline $15 \mathrm{~min}$ & dry air, $\mathrm{p}=940 \mathrm{mbar}, \mathrm{t}_{1}=10 \mathrm{~min}$ & ${ }^{18} \mathrm{O}_{2}, \mathrm{p}=200 \mathrm{mbar}, \mathrm{t}_{2}=5 \mathrm{~min}$ \\
\hline $60 \mathrm{~min}$ & dry air, $\mathrm{p}=940 \mathrm{mbar}, \mathrm{t}_{1}=40 \mathrm{~min}$ & ${ }^{18} \mathrm{O}_{2}, \mathrm{p}=200 \mathrm{mbar}, \mathrm{t}_{2}=20 \mathrm{~min}$ \\
\hline $300 \mathrm{~min}$ & dry air, $\mathrm{p}=940 \mathrm{mbar}, \mathrm{t}_{1}=240 \mathrm{~min}$ & ${ }^{18} \mathrm{O}_{2}, \mathrm{p}=200 \mathrm{mbar}, \mathrm{t}_{2}=60 \mathrm{~min}$ \\
\hline
\end{tabular}

Tab. 2 : Two-stage-oxidation experiments $\left(\mathrm{T}=1200^{\circ} \mathrm{C}\right)$

SNMS was chosen as the analytical method because of its good depth resolution and the possibility of quantifying the data obtained. Nevertheless, a problem with the interpretation of SNMS data is the transformation of intensity vs. sputter time profiles to concentration vs. depth profiles.

As a first step, relative sensitivity factors referring to aluminium are calculated from the SNMS data. This is easily possible for the metals ( $\mathrm{Cr}, \mathrm{Fe}$ ) without any additional standard because the chemical composition of the

1 The preparation of these specimens was carried out by the Ecole des Mines, St. Etienne, France.

2 For details the authors should be contacted. 
substrate material is well known ${ }^{3}$. The greater problem is to deternine this factor for oxygen. Therefore samples with a 'thick' dense aluminium oxide scale are sputtered. Assuming that the scale is stoichiometric $\mathrm{Al}_{2} \mathrm{O}_{3}$, the relative sensitivity factor for oxygen then also can be calculated. The sensitivity factors so calculated are in good accordance with values in the literature. With this information the mass spectrometric intensity (measured in counts per second) can be transformed into atomic concentration $(\Delta \mathrm{c}<2$ at $\%$ ).

The next step is to transform the sputter time axis into a depth axis. If one takes into account the change of the sputter yield and the change of the material density as a function of sputter time or depth, respectively, and if the crater depth is known (using a mechanical profilometer) this non-linear transformation can be carried out[6].

In this context, special attention has to be paid to the depth resolution obtained by sputter techniques.

Surface roughness of the oxide scale depends on the substrate material, on oxidation period, on oxidation atmosphere and on temperature. It is important to examine the surface topography after oxidation because it limits the depth resolution of SNMS. Under the same oxidation conditions the least roughness is observed for the two alloys containing no yttrum (materials A and B). Such behaviour can be explained by different microstructures of the substrate (see Fig. 1). The yttrium-bearing alloys (materials $C$ and $D$ ) contain the reactive element in intermetallic particles whose size is in the range of a few $\mu \mathrm{m}$ (see Fig. 2). Silicon enrichment in the dark particles of material $\mathrm{C}$ is a result of the polishing procedure. In the magnification shown in Fig. 3 the surface roughness prior to oxidation would show up as a horizontal line.

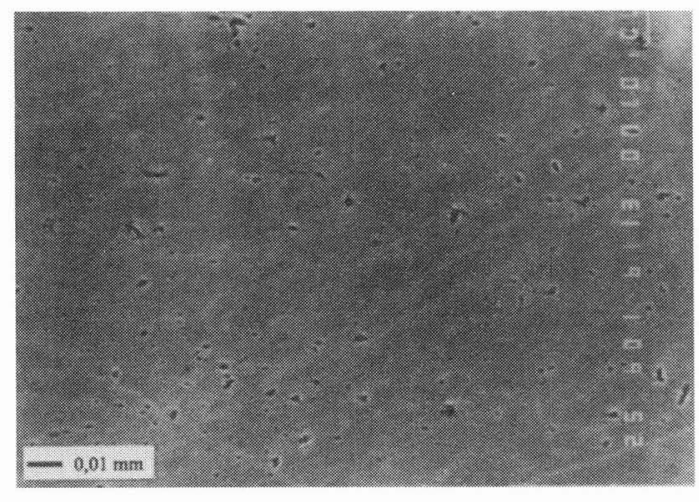

Fig. 1 : SEM (material A)

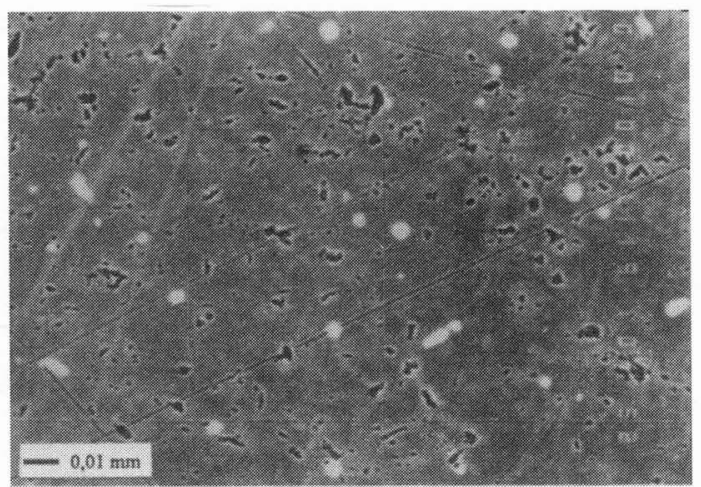

Fig. 2 : SEM (material C)

\begin{tabular}{|c|c|c|c|c|c|c|c|c|c|c||}
\hline \multicolumn{4}{|c|}{ Material A } & \multicolumn{4}{|c|}{ Material C } \\
\hline Al & $\mathrm{Si}$ & $\mathrm{Cr}$ & $\mathrm{Fe}$ & $\mathrm{Y}$ & chemical composition, w\% & $\mathrm{Al}$ & $\mathrm{Si}$ & $\mathrm{Cr}$ & $\mathrm{Fe}$ & $\mathrm{Y}$ \\
\hline 5,0 & - & 20,2 & bal. & - & average composition (producer) & 5,0 & - & 19,7 & bal. & 0,1 \\
\hline 4,8 & 0,0 & 20,8 & 74,4 & 0,0 & matrix by EDX & 4,8 & 0,1 & 20,6 & 74,4 & 0,1 \\
\hline \multicolumn{3}{|c|}{ topographical defects } & dark particles (EDX) & 1,2 & 45,3 & 13,0 & 40,5 & 0,0 \\
\hline- & - & - & - & - & bright particles (EDX) & 7,0 & 0,0 & 11,7 & 66,6 & 14,7 \\
\hline
\end{tabular}

Tab. 3 : EDX analysis of material $\mathrm{A}$ and $\mathrm{C}$

It can be observed that the roughness increases with increasing oxidation time. In Fig. 3 the scale roughness of two alloys (matrials $\mathrm{A}$ and $\mathrm{C}$ ) is compared after $15 \mathrm{~min}, 60 \mathrm{~min}$ and $300 \mathrm{~min}$ oxidation time at $1200^{\circ} \mathrm{C}$. As

3 The concentration of yttrium and sulphur is beneath the detection limit of the SNMS equipment used(VG-SIMS/SNMSLab, Ecole des Mines de Nancy). 
substrate material is well known ${ }^{3}$. The greater problem is to deternine this factor for oxygen. Therefore samples with a 'thick' dense aluminium oxide scale are sputtered. Assuming that the scale is stoichiometric $\mathrm{Al}_{2} \mathrm{O}_{3}$, the relative sensitivity factor for oxygen then also can be calculated. The sensitivity factors so calculated are in good accordance with values in the literature. With this information the mass spectrometric intensity (measured in counts per second) can be transformed into atomic concentration $(\Delta c<2$ at $\%$ ).

The next step is to transform the sputter time axis into a depth axis. If one takes into account the change of the sputter yield and the change of the material density as a function of sputter time or depth, respectively, and if the crater depth is known (using a mechanical profilometer) this non-linear transformation can be carried out[6].

In this context, special attention has to be paid to the depth resolution obtained by sputter techniques.

Surface roughness of the oxide scale depends on the substrate material, on oxidation period, on oxidation atmosphere and on temperature It is important to examine the surface topography after oxidation because it limits the depth resolution of SNMS. Under the same oxidation conditions the least roughness is observed for the two alloys containing no yttrum (materials A and B). Such behaviour can be explained by different microstructures of the substrate (see Fig. 1). The yttrium-bearing alloys (materials $C$ and $D$ ) contain the reactive element in intermetallic particles whose size is in the range of a few $\mu \mathrm{m}$ (see Fig. 2). Silicon enrichment in the dark particles of material $\mathrm{C}$ is a result of the polishing procedure. In the magnification shown in Fig. 3 the surface roughness prior to oxidation would show up as a horizontal line.

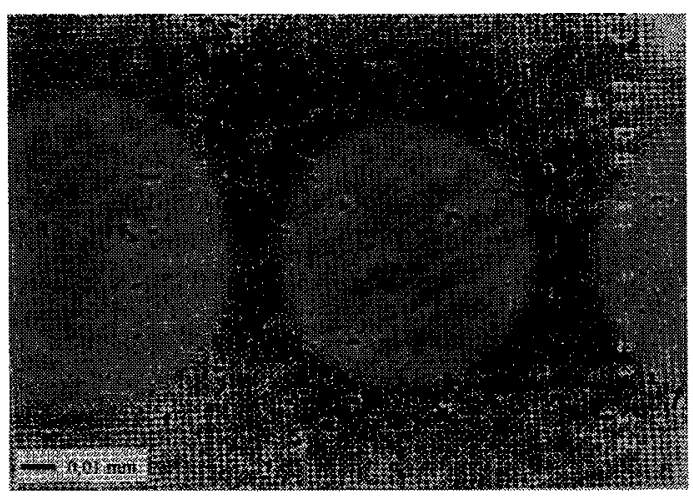

Fig. 1 : SEM (material A)

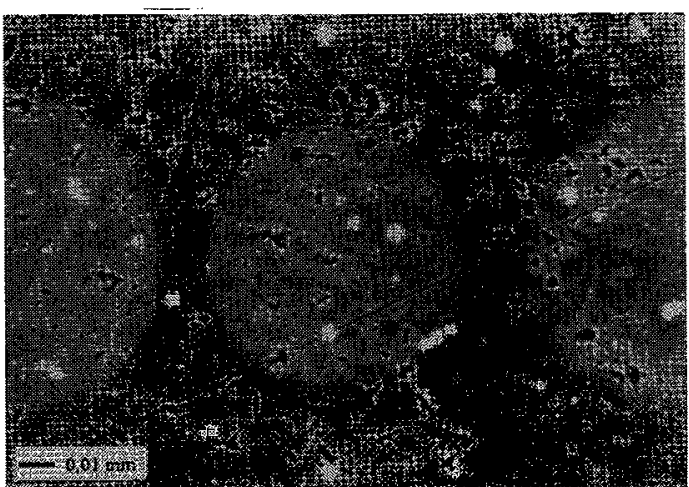

Fig. 2 : SEM (material C)

\begin{tabular}{|c|c|c|c|c|c|c|c|c|c|c||}
\hline \multicolumn{4}{|c|}{ Material A } & \multicolumn{4}{|c|}{ Material C } \\
\hline $\mathrm{Al}$ & $\mathrm{Si}$ & $\mathrm{Cr}$ & $\mathrm{Fe}$ & $\mathrm{Y}$ & chemical composition, w\% & $\mathrm{Al}$ & $\mathrm{Si}$ & $\mathrm{Cr}$ & $\mathrm{Fe}$ & $\mathrm{Y}$ \\
\hline 5,0 & - & 20,2 & bal. & - & average composition (producer) & 5,0 & - & 19,7 & bal. & 0,1 \\
\hline 4,8 & 0,0 & 20,8 & 74,4 & 0,0 & matrix by EDX & 4,8 & 0,1 & 20,6 & 74,4 & 0,1 \\
\hline \multicolumn{3}{|c|}{ topographical defects } & dark particles (EDX) & 1,2 & 45,3 & 13,0 & 40,5 & 0,0 \\
\hline- & - & - & - & - & bright particles (EDX) & 7,0 & 0,0 & 11,7 & 66,6 & 14,7 \\
\hline
\end{tabular}

Tab. 3 : EDX analysis of material $\mathrm{A}$ and $\mathrm{C}$

It can be observed that the roughness increases with increasing oxidation time. In Fig. 3 the scale roughness of two alloys (matrials $\mathrm{A}$ and $\mathrm{C}$ ) is compared after $15 \mathrm{~min}, 60 \mathrm{~min}$ and $300 \mathrm{~min}$ oxidation time at $1200^{\circ} \mathrm{C}$. As

3 The concentration of yttrium and sulphur is beneath the detection limit of the SNMS equipment used(VG-SIMS/SNMSLab, Ecole des Mines de Nancy). 


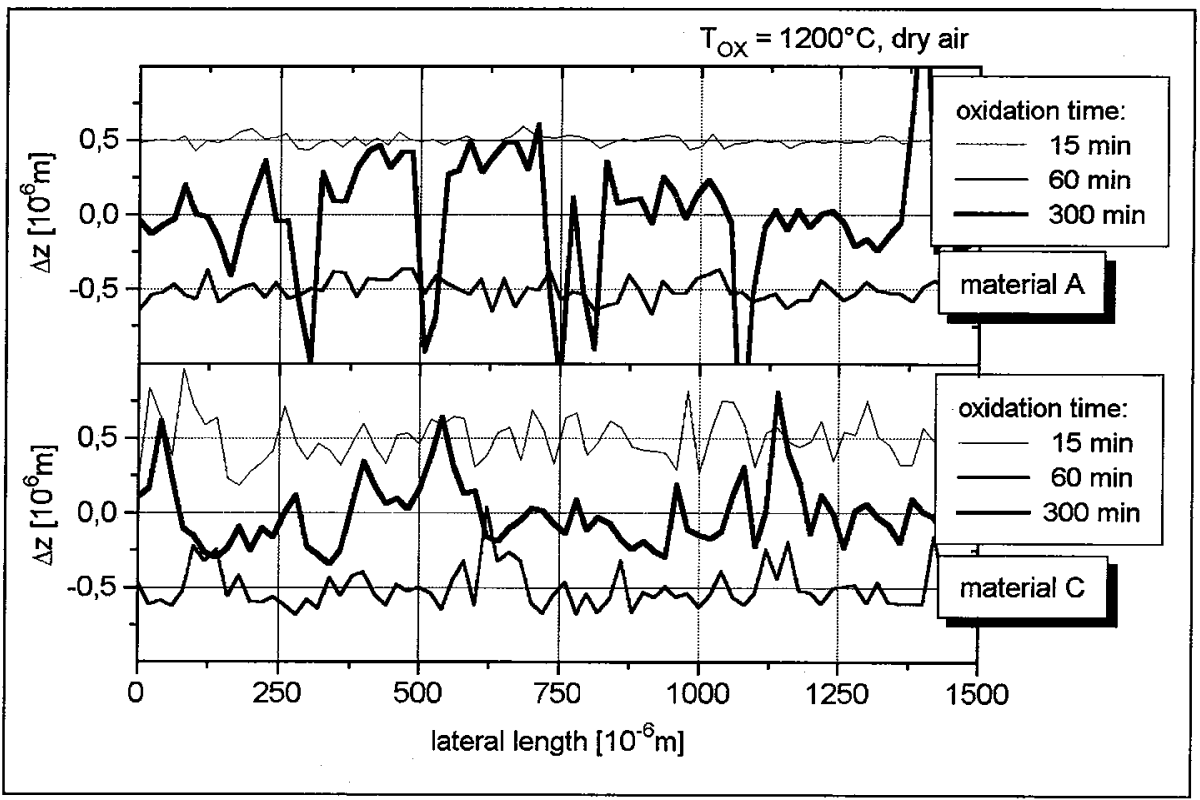

Fig. 3: Scale roughness after oxidation

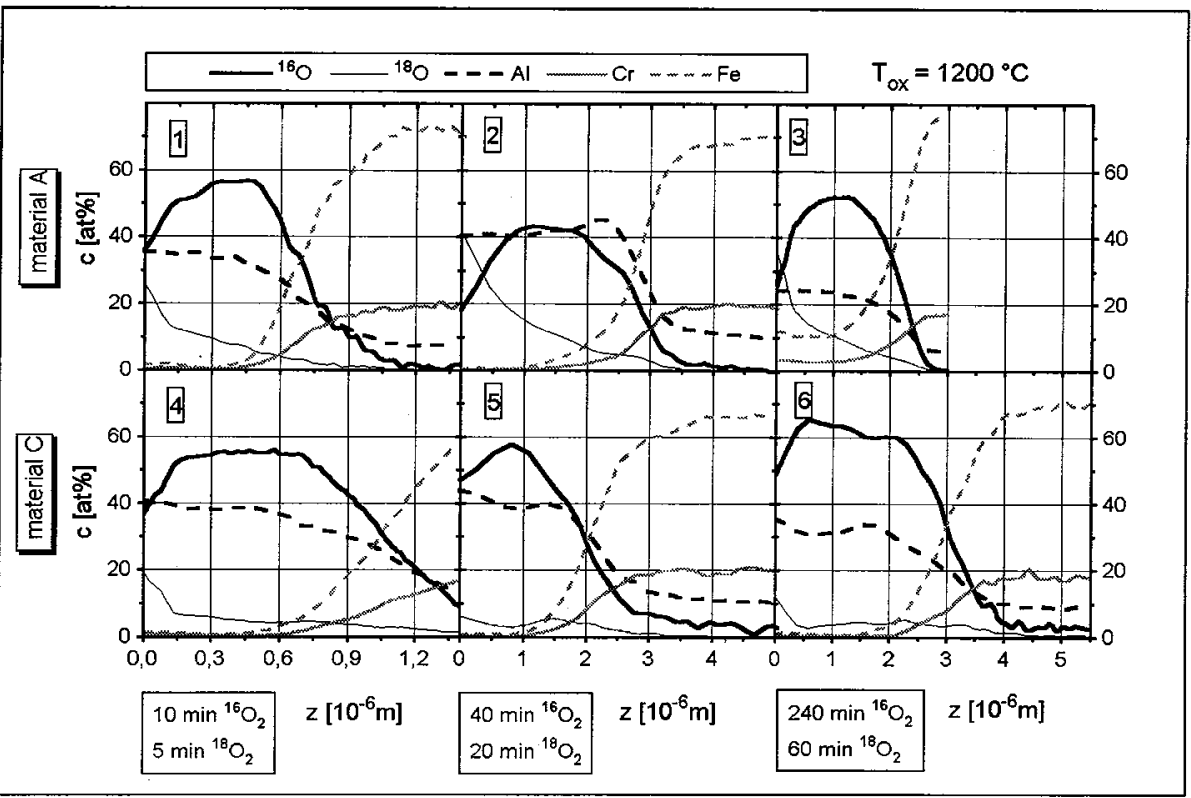

Fig. 4: SNMS data of the alloys $A$ and $C$ 
can be seen from the figure, the scale roughness of material A after $15 \mathrm{~min}$ is less than that of material $\mathrm{C}$. It rises slowly ( $\mathrm{t}_{\mathrm{ox}}=60 \mathrm{~min}$ ) but shows a dramatic value after $300 \mathrm{~min}$ oxidation time. In contrast, the roughness of material $\mathrm{C}$ changes only slightly with increasing oxidation time.

This behaviour is also reflected in the SNMS profiles. Fig. 4 shows SNMS profiles of the same alloys as those shown in Fig. 3. The link between the results of the roughness measurements and the SNMS measurements can be seen clearly in Fig. 4 : in spectrum number 3, the effect of the occurrence of chromium and iron 'on top of the surface' can be understood if one takes into account the strongly corrugated morphology of the oxide surface after 300 min oxidation time. The surface area analyzed is in all cases $600 \mu \mathrm{m} * 600 \mu \mathrm{m}$, which clearly covers the characteristic distance between two ridges or valleys, respectively. Therefore, the scale appears to be thinner than the scale after 60 min oxidation time. As a conclusion it must be said that in addition to the SNMS data, quantitative information on surface roughness is important if the situation is not to be misjudged.

\section{RESULTS}

The predominant diffusion mechanism across the oxide scale depends on the substrate composition in the range of $\alpha-\mathrm{Al}_{2} \mathrm{O}_{3}$ formation. From Fig. 4 it is evident that the alloys without yttrium show predominant outward aluminium diffusion whereas the yttrium-bearing alloys exhibit simultaneous aluminium outward and oxygen inward diffusion. This means that the reactive element effect can be partially interpreted as an effect influencing the oxide growth mechanism.

Sulphur and the reactive element yttrum yield significant differences of oxide scale composition and microstructure during oxidation at $1200^{\circ} \mathrm{C}$. Obviously, ytrium reduces the concentration of chromium and iron in the oxide scale. Sulphur itself leads to surprisingly high chromium and iron concentrations in the oxide scales. The alloy with the higher sulphur concentration shows oxide scale spallation after $5 \mathrm{~h}$ at $1200^{\circ} \mathrm{C}$.

\section{ACKNOWLEDGEMENTS}

Part of this work was supported by the European Commission (Brite-EuRam contract BRE2-0605 : publication of this paper is authorized by the scientific officer and the partners of the project). Further, substantial funding by the Deutsche Forschungsgemeinschaft (DFG) is gratefully acknowledged.

\section{REFERENCES}

[1] G. Ben Abderrazik, G. Moulin, A. M. Huntz and R. Berneron, J. Mat. Sci. 19 (1984) 3173-3184

[2] J. Jedlinski, Solid State Phenomena, 21 \& 22 (1992) 335-390

[3] W. J. Quadakkers, A. Elschner, W. Speier and H. Nickel, Appl Surf. Sci. 52 (1991) 271-287

[4] W. E. King (ed.), The Reactive Element Effect on High Temperature Oxidation - After Fifty Years (Materials Science Forum, Trans Tech Publications Ltd. Swizerland, 1989)

[5] G. H. Meier, F. S. Pettit and J. L. Smialek, Materials and Corrosion 46 (1995) 232-240

[6] A. Wucher, H. Oechsner, Fresenius Z. Anal Chem. 333 (1989) 470-473 